\section{Journal of Computer Networks, Architecture and High Performance Computing}

Volume 3, Number 2, July 2021

https://doi.org/10.47709/cnahpc.v3i2.1006
Submitted : 28 June 2021

Accepted : 6 July 2021

Published : 5 August 2021

\title{
Point of Sale Framework-Based Code Igniter and Model View Controller Using Lighthouse Testing
}

\author{
Muhammad Syaifudin ${ }^{1 *}$, Fauziah $^{2)}$, Ben Rahman ${ }^{3)}$ \\ 1)2)3) Universitas Nasional, Indonesia \\ ${ }^{1)}$ m.syaifudin26@gmail.com, ${ }^{2)}$ fauziah@civitas.unas.ac.id, ${ }^{3)}$ benrahman@civitas.unas.ac.id
}

\begin{abstract}
The success of companies engaged in the field of distributors is not only from good and smart human resources, but how ready the company's way to provide tools or programs supporting the work of employees. Some of the problems are the administration system between the company's internal divisions, so there are restrictions on the processing of input data, processes, outputs that are still manual. Web Application is made to facilitate employees to conduct administrative activities with the access role of each user admin division, for example inventory data, creation of sales invoices, road letters, procurement forms and bookkeeping. In addition, The Web View application is already responsive in this sense can adjust the device PC / Tablet / Mobile, then for visualization of data calculation already using cart / data graphics in real time, and there is also a feature preview, download and print JPEG, PNG, PDF, Barcode and QR code. Web Testing This application with black box method and shows it is running well and no error method, so it can be declared passed. Web Creation This application involves the LTE 2.0 Admin Template with bootstrap CSS, for programmer frameworks using MVC model view controllers that exist in the Code Igniter 3.0 framework so that it is faster and easier to implement or developed in other field companies or in the manufacturing industry. Tests using lighthouse for perform by $94 \%$ showed that the application designed to have a good performance for display results, and its access value of $60 \%$, indicating that the process related to responsiveness between users is appropriate both using PC / Tablet / Mobile
\end{abstract}

Keywords: Point of Sale; Database; MVC; Ajax; Lighthouse Testing

\section{INTRODUCTION}

Distribution a product is a very important party for manufacturers and consumers. Distributors are people who play a very role in the distribution of goods. The function of distributors is to create a smooth flow of marketing, in the era of globalization as it is today, the business world has grown very rapidly and become increasingly competitive. Along with the development of the business world, information technology is required to develop and innovate in order to keep pace with the progress of the business world, rapid data exchange is needed by a company. With this point of sale is made to facilitate employees to conduct administrative activities, Example: inventory data, creation of sales invoices, road letters, procurement forms and bookkeeping. A company that has a cooperative relationship with other parties, one of which is for companies that at any time have data in process, work for logging and making invoices can be done by several related divisions manually, but has many shortcomings. Human error factor is a factor that can cause many problems, such as data collection errors, lack of data input, invoice creation errors, miscalculations, expenses and so on, which causes loss of time and operational costs for the company. Web Application point of sale is made to minimize administrative activities and data logging manually, With the existence of this web application, then every invoicing and data logging can be done quickly by referring to the existing database in the company, so that this will make it easier for employees to do the job effectively and efficiently. Point of Sale POS) has an application system that is applied to distributor companies to handle data processing between divisions including procurement admins, warehouse admins and sales admins. This in general must be present and important in strategic decision making by business people, offices or large-scale industries. The purpose of creating a web application point of sale is research in this Final Task to design a data processing system between divisions with access role access of each user admin, and divide the system into 4 of them there are admin supervisor, procurement admin,

* Corresponding author

This is an Creative Commons License This work is licensed under a

Creative Commons Attribution-NoDerivatives 4.0 International License. 


\section{Journal of Computer Networks, Architecture and High Performance Computing}

Volume 3, Number 2, July 2021

https://doi.org/10.47709/cnahpc.v3i2.1006
Submitted : 28 June 2021

Accepted : 6 July 2021

Published : 5 August 2021

warehouse admin and sales in a well-structured. In the making of this research discussion of problems has limitations on problems, among others, the creation of a point of sale application web application aimed at the scope of the distributor company, using the LTE Admin Template 2.0 with bootstrap CSS, for the template language program using MVC model view controller that is on the framework Code Igniter 3.0 and for databases using MariaDB, the results will be simulated in the web browser locally area / online hosting.

\section{LITERATURE REVIEW}

MVC (Model-View-Controller) architecture of CodeIgniter. In this approach, the PHP framwork meta model is considered as a platform Specific model (PSM). Its instances are used as inputs to generate the source code through transformation rules carried out by Acceleo. This proposal is validated through the use of our approach to generate CRUD (Create, Read, Update and Delete) applications (Arrhioui et al., 2017), We have study the variation of coupling coefficients with the width of waveguide and realized that single mode waveguide with smaller core width have lower critical power. Here, we have proposed a noble design of NLDC with asymmetric waveguide along the length with lower critical power as compare to the symmetric waveguide (Singh et al., 2017), This model is based on a set of comparison criteria based on the Intrinsic durability, industrialized solution, technical adaptability, strategy, technical architecture, and Speed criteria. Results show that the values of these criteria allow developers to easily and properly choose the framework that best meets their needs (Benmoussa et al., 2019), The multi-criteria decision model is implemented as a Decision Matrix and combines set theory based option filtering with the MAUT method for option ranking (Rodič et al., 2017), The term Ajax and related technologies are discussed here. Also working of Ajax technologies and basic idea of Ajax based rich web applications is discussed (. ANKURKAR, 2015), As result of this research we can find out the development was standardized and non-business logic relationships automatically processed, there was much scalability so this gives us more efficiency through the implementations (Thakir Mahmood et al., 2019), In this study we aim to identify the elements that impact on agility in developing software products, in a gradual approach, from the traditional waterfall model towards approaches like Scrumban. Additionally, we will understand the social dimension of using agile methodologies in software development (STOICA et al., 2016), This research also highlights limitations of Scrumbanfall like team members and their roles and capabilities for the large scaled project having team members in distributed environment, which open the door for next level of research to overcome such challenges using further hybridization of Scrumbanfall (Bhavsar et al., 2020), The making of this POS application starts from the collecting all the data needed using observation and interview methods, designing an application models with an object-based approach diagram with application design tools in the form of a flowchart and Unified Modeling Language (UML) until the implementation of this POS application. With the application of the point of sales (POS) application can help the tasks of all stakeholders or related parties directly related to the POS application (Kambivi et al., 2020), The result of the evaluation was ranked with Functional Suitability as the highest. The evaluation is based on ISO 25010. This shall help the client to stay away from their former data storing procedure and move on to the automated world (Miguel et al., 2019), The development of a prototype that encompasses solutions to solve the aforementioned problems was used to validate the design and initial results showed that the client supports the relevance of the design (Sison et al., 2019), The data analytics helps in analyzing the information access pattern of the users. The information access pattern can be helpful in identifying the learning behavior traits of an individual. Moreover, machine learning along with data mining has opened up new avenues. The combination of data analytics and machine learning may be used to generate targeted recommendations (Industry, 2011), A case study of evaluating a POS system in Bangladesh has demonstrated that the proposed model can provide a comprehensive evaluation of POS from 12 usability factors. Also, different demands from different type of customers are also be revealed by the model (Kabir \& Han, 2016), The completion of this investigation identified the essential factor of POS based on cloud computing adoption which appropriates with IT Users and Entrepreneur's. The most significant factor in cloud computing adoption for point of sales is security and ease of use. Based on that result this study purpose the POS infrastructure for SME's in Indonesia especially in Surabaya (Paramita, 2019), The study results make evidence of the conclusion that the relationship between EPOS and Supply Chain Performance is positive (Journal et al., 2017)

\footnotetext{
* Corresponding author
}

This is an Creative Commons License This work is licensed under a 


\section{Journal of Computer Networks, Architecture and High Performance Computing}

Submitted : 28 June 2021

Volume 3, Number 2, July 2021

https://doi.org/10.47709/cnahpc.v3i2.1006

Accepted : 6 July 2021

Published : 5 August 2021

\section{METHOD}

The Application Web Design Framework is with the MVC (Model View Controller) method where this is what is in the Code Igniter 3.0 framework. MVC method is also commonly referred to as software design pattern which is a program in 3 separate parts that are interconnected, the functions of the program part is different namely Model (related to the database in order to be processed, update and input data), View (set the view to be easier to understand users) then the last is controller (connecting models and views), Process and MVC Method in Fig 1.

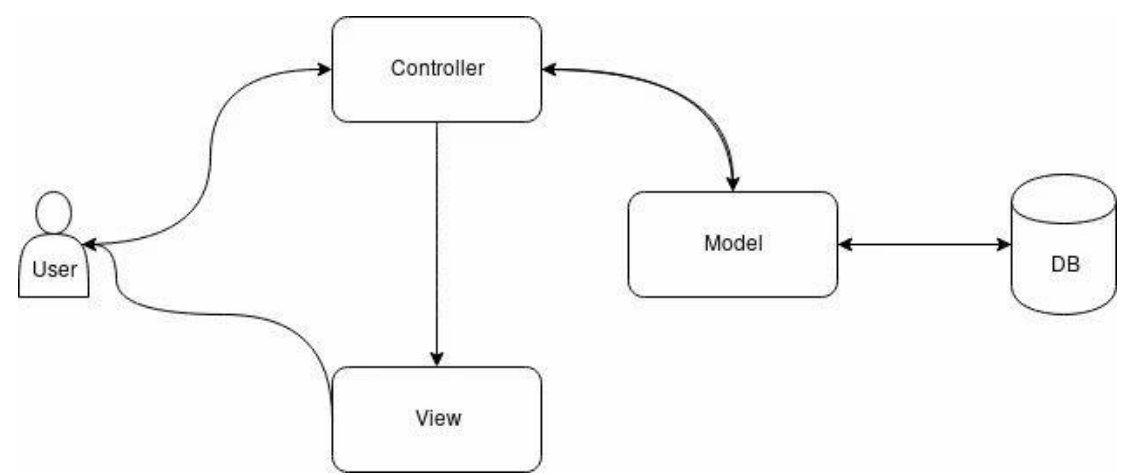

Fig. 1. MVC (Model View Controller)

1. The first stage is a survey of several distributor companies to collect needs data, which aims to find out the current problem.

2. The second stage is the analysis of needs, which is done to find the right solution to solve problems that exist in distributor companies as already known in the collection of data needs.

3. The third stage is the design of the application web. The results of the analysis that has been obtained previously poured in the design to determine what functions will be contained in the web application to meet the needs of a particular application.

4. The fourth stage is the result of the existing design being implemented into the program code so as to form a web application that can be used properly.

5. The fifth stage is testing, the testing method used to test the system is to use the Lighthouse testing method (Dev tools Google Chrome). This testing method will test all components and system functionality whether the software is running correctly and in accordance with the objectives to be achieved. This test is done on the web application to identify and correct errors. The result of this stage is a web application that has been free from errors, can run in accordance with its functions and ready to use.

\section{Analysis of Old Systems}

After conducting surveys, data collection and observation directly with the relevant parties to the distributor company, the results of the need data obtained where the work process between divisions is divided into several stages that have been summarized in the table can be seen in Table 1.

Table. 1. Old System Analysis

\begin{tabular}{ccc}
\hline Process & Information & Obstacles \\
\hline $\begin{array}{c}\text { Registration of new } \\
\text { admin users by } \\
\text { division }\end{array}$ & $\begin{array}{c}\text { user_id,username,passwor } \\
\text { d,name,address,level }\end{array}$ & $\begin{array}{c}\text { The registration process is still manual and the } \\
\text { search for admin users is still manual }\end{array}$ \\
$\begin{array}{c}\text { Addition of Item } \\
\text { Data, Item Type, } \\
\text { Inventory, etc. }\end{array}$ & $\begin{array}{c}\text { item id, barcode, item } \\
\text { name, item type, stock and } \\
\text { price }\end{array}$ & $\begin{array}{c}\text { The process of data collection of goods is still } \\
\text { manual by using a notebook }\end{array}$
\end{tabular}

\footnotetext{
* Corresponding author
} 


\section{Journal of Computer Networks, Architecture and High Performance Computing}

Submitted : 28 June 2021

Volume 3, Number 2, July 2021

https://doi.org/10.47709/cnahpc.v3i2.1006

\begin{tabular}{|c|c|c|}
\hline $\begin{array}{l}\text { Separation of access } \\
\text { to procurement } \\
\text { admin, warehouse } \\
\text { admin, sales admin } \\
\text { and supervisor }\end{array}$ & user_id, level & $\begin{array}{l}\text { The user access process is still one so it does not } \\
\text { guarantee data security in each division }\end{array}$ \\
\hline $\begin{array}{l}\text { Making Invoices } \\
\text { (Sales Invoices, } \\
\text { Travel Letters, } \\
\text { Procurement Forms } \\
\text { and Bookkeeping) }\end{array}$ & $\begin{array}{l}\text { form id, invoice, amount, } \\
\text { note, date and user id }\end{array}$ & $\begin{array}{c}\text { The process of making invoices is still manual, the } \\
\text { calculation of the amount data is still being } \\
\text { calculated one by one }\end{array}$ \\
\hline
\end{tabular}

The table in Table. 1 shows the results of collecting old data and direct observations of distributor companies by showing several work processes in each division.

\section{Updateability of The Analysis Results}

Understanding the nature and function of the system to be built, the analysis carried out must understand the domain information, division of functions and behaviors required and reference at the previous stage, the system built will be able to be used by 4 user admins, namely admin supervisor, procurement admin, warehouse admin and sales. The description of each admin can be seen in Table. 2.

Table. 2. Description of Admin User

\begin{tabular}{|c|c|c|c|}
\hline No & User & Description & Level \\
\hline 1 & Supervisor & $\begin{array}{c}\text { CRUD User admin, access } \\
\text { all features of the admin } \\
\text { user }\end{array}$ & 1 \\
\hline 2 & Procurement Admin & $\begin{array}{l}\text { Procurement Master (data } \\
\text { type), Supplier, Duplicate } \\
\text { Invoice, Procurement } \\
\text { Report }\end{array}$ & 2 \\
\hline 3 & Warehouse Admin & $\begin{array}{l}\text { Stock in, Stock Out, } \\
\text { Warehouse Invoice, } \\
\text { Warehouse Report }\end{array}$ & 3 \\
\hline 4 & Sales Admin & $\begin{array}{c}\text { Customer Data, Goods } \\
\text { Data, Sales Invoice, Invoice } \\
\text { Bookkeeping }\end{array}$ & 4 \\
\hline
\end{tabular}

The table in Table. 2 shows the results of the admin user access role design that has been adjusted to the distribution company division which will later be used to login at the point of sale.

\section{Supporting Tools and Software}

Laptop (i3/8GB/500GB), OS (Linux Debian 10). Server (Apache 2, MYSQL/MariaDB), Text Editor (Visual Studio Code), Programming Languages (PHP, JS, HTML, CSS)

\section{Design System Role Access User Admin}

Describing the details of the work of the admin user on the system to be used by the distributor company, there is division for each user admin has different menus and functions according to the needs of each admin features as described in the Mind Map diagram in Fig. 2.

\footnotetext{
* Corresponding author
} 


\section{Journal of Computer Networks, Architecture and High Performance Computing}

Volume 3, Number 2, July 2021

https://doi.org/10.47709/cnahpc.v3i2.1006
Submitted : 28 June 2021

Accepted : 6 July 2021

Published : 5 August 2021

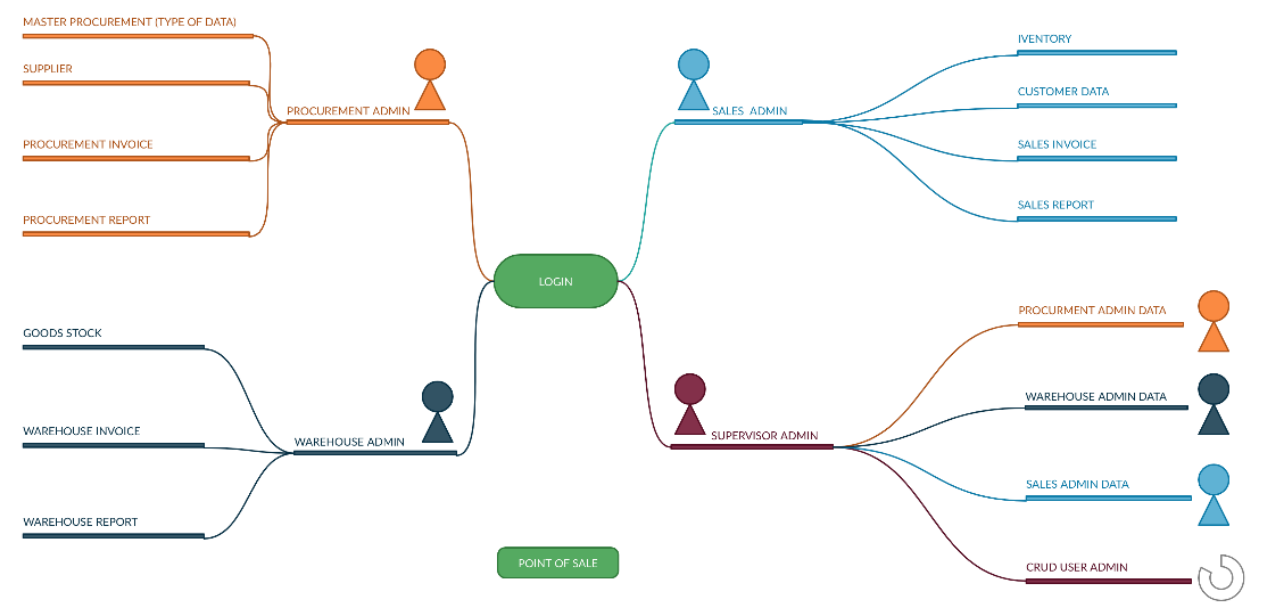

Fig. 2. Diagram Mind Map Role User Access

The mind map diagram in fig. 2 above shows the results of designing the point of sale menu feature that has been adjusted to the distribution company division that has been determined according to the division admin.

\section{Create a Flowchart System}

Outline the web application that will be created using flowchart for more detailed explanation. Web Application can be used by user admin with user admin permissions that have been specified. User admin supervisor in doing all the features contained in this web application, while other admin users have limitations of features that have been set by the user admin supervisor. To use this web application must first enter your username and password to be able to login. Then the system will check the access role of the username, password and user level in the database. If the username and password of the admin user are in the database. Then it will be done checking the role of username, password and user level. Furthermore, the web application will display the main page of the dashboard and the features that have been specified in accordance with the user admin access role respectively. If the username and password data does not exist or does not match the time of login, it will display an error alert message and the admin user must login again, can be seen in Fig. 3.

\footnotetext{
* Corresponding author
} 


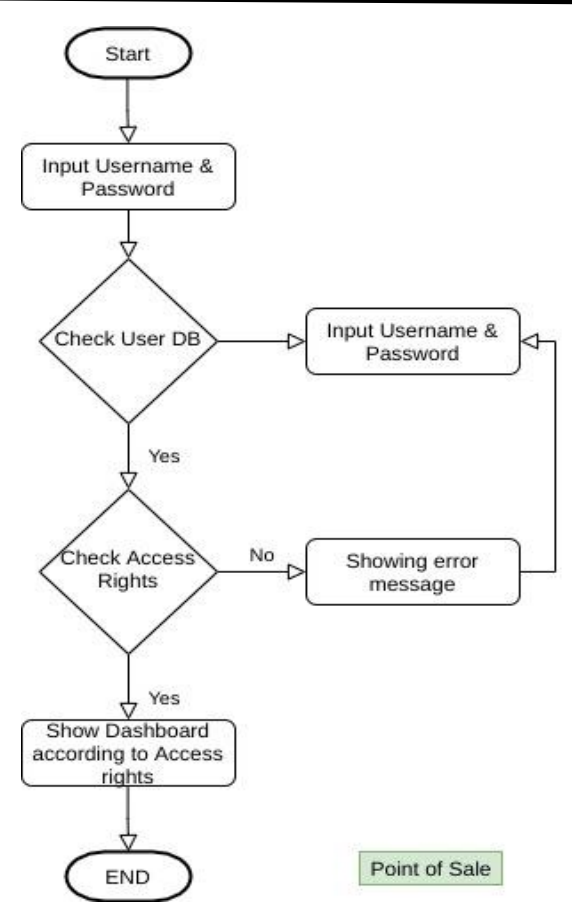

Fig. 3. Flowchart outline web application

Fig. 3 above shows the point of sale flowchart, where the user must first login with the specified admin access role, if the login fails, there will be an error notification and then it will be returned to re-login.

\section{Application Hierarchy}

Application web page, there are various menus that can be selected according to the terms of user admin features in each division. The hierarchy of these menus can be seen in Fig. 4.

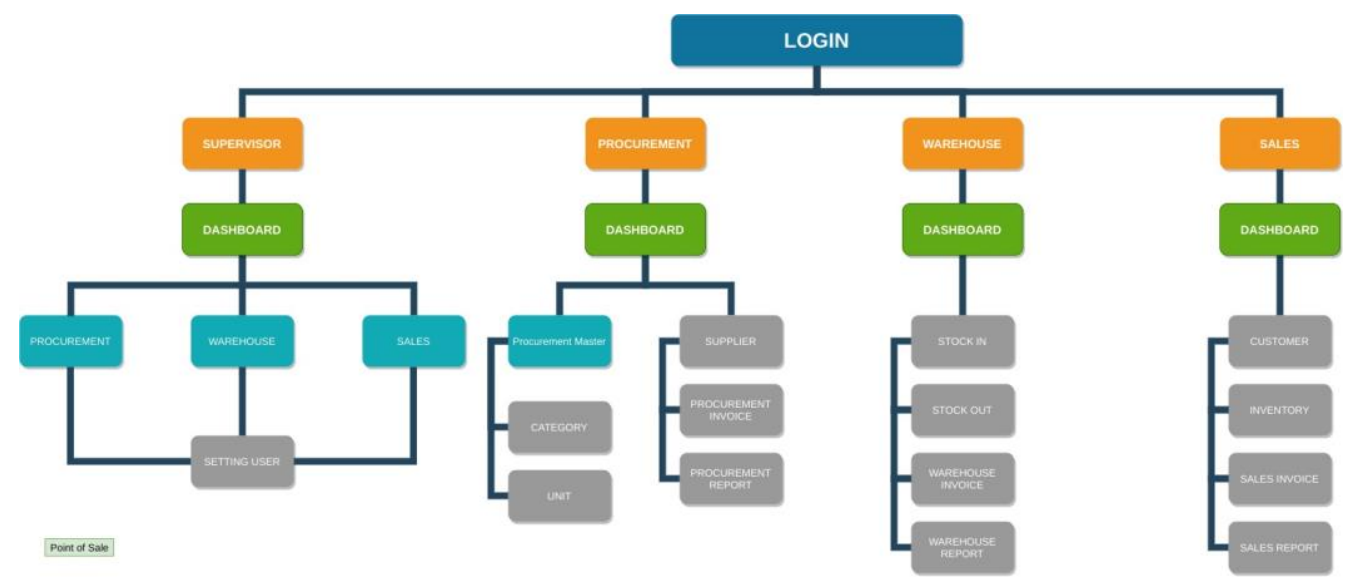

Fig. 4. Application Web Hierarchy

The hierarchy diagram in fig. 4 above shows the results of the design of the menu feature derivative after logging in at the point of sale in a structured manner, by adjusting to the respective admin user roles.

* Corresponding author 


\section{Journal of Computer Networks, Architecture and High Performance Computing}

Submitted : 28 June 2021

Volume 3, Number 2, July 2021

https://doi.org/10.47709/cnahpc.v3i2.1006

Accepted : 6 July 2021

Published : 5 August 2021

\section{Coding Script}

For php code writing in the application web program involves the MVC Model View Controller method where the writing of this code will be easier and more structured, It is necessary to call the user level access that has been made can be seen in Fig. 5.

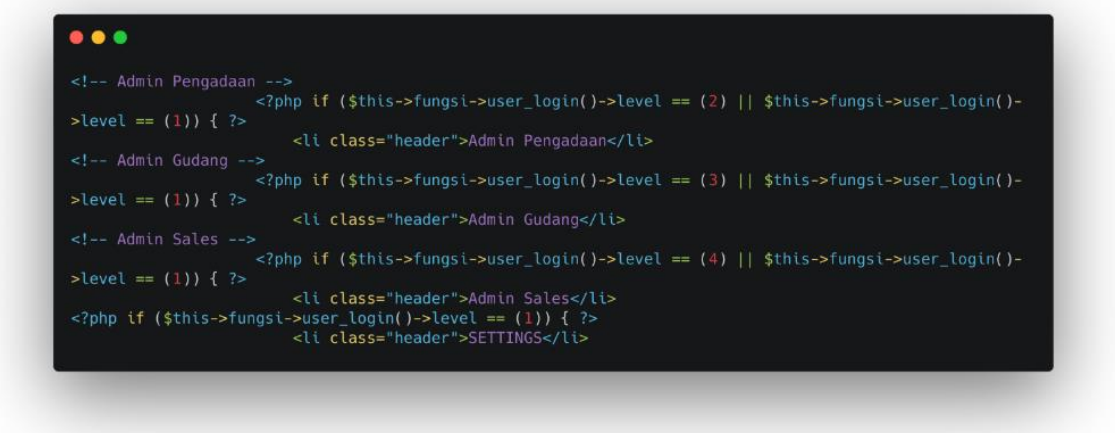

Fig. 5. Index and Template PHP

The following above in Fig. 5 is a coding script at the index using the PHP programming language by calling each user id that has been determined.

\section{RESULT}

The result of this test conducted at the beginning of the web application is run in google chrome Browser will be displayed a login page before being able to use the features inside the application that is divided into 4 admin users. but before testing, there are user data that have been added to the database as follows :

Admin Supervisor (Username : supervisor; Password : 12345), Procurement Admin (Username : procurement; Password : 12345), Warehouse Admin (Username : warehouse; Password : 12345), Admin Sales (Username : sales; Password : 12345).

\section{Testing/ Verification Web Application}

Testing with admin supervisor access user with level id (1) can be seen in Fig. 6 and Fig. 7.

\footnotetext{
* Corresponding author
} 


\section{Journal of Computer Networks, Architecture and High Performance Computing}

Volume 3, Number 2, July 2021

https://doi.org/10.47709/cnahpc.v3i2.1006
Submitted : 28 June 2021

Accepted : 6 July 2021

Published : 5 August 2021

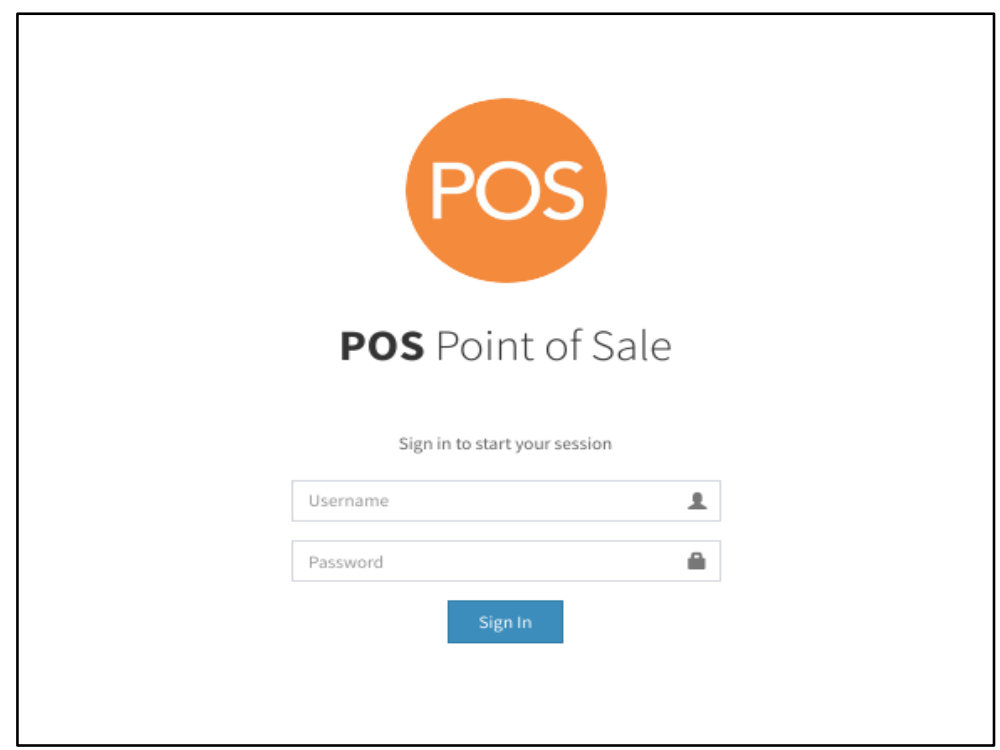

Fig. 6. Login Page View

In Fig. 6 is the start page on the point of sale website where the admin user must fill in the specified username and password, after that the user presses or clicks the sign in button, the password is already using shal security.

This login page user admin supervisor must do the login process by entering the username and password that has been added to the database, this login page is for all other admin users, the difference is only the username and password of each - each of which has been added to the database.

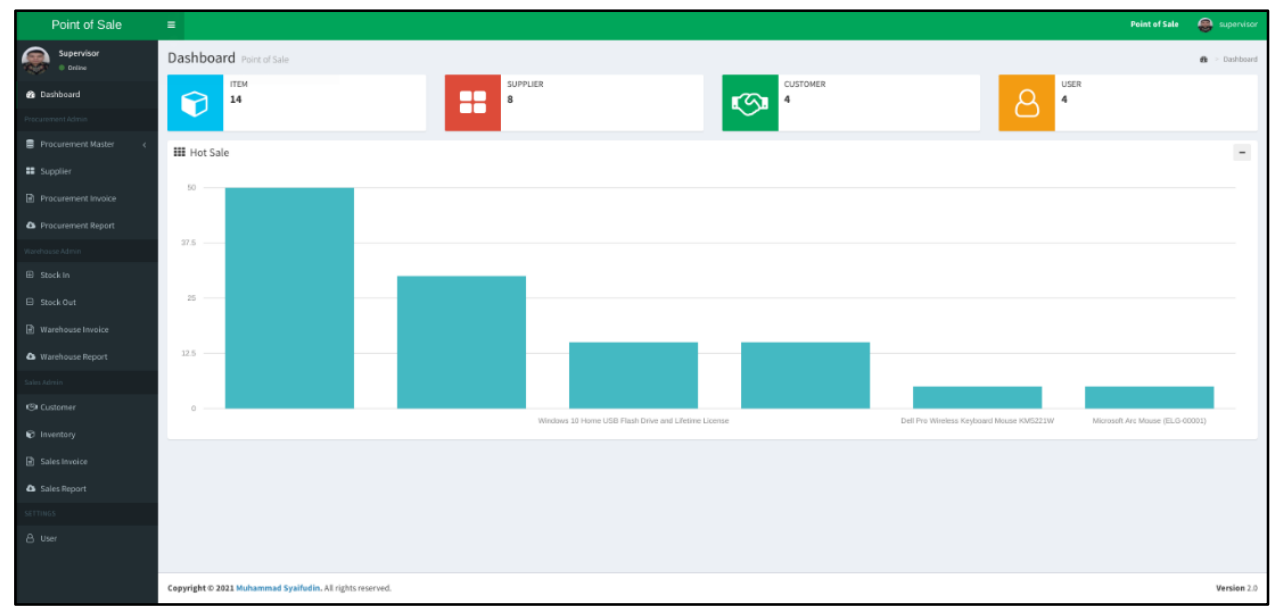

Fig. 7. Dashboard Page View of The Supervisor Admin

On the page dashboard user admin supervisor shows some menu features and can access all the data owned with user admin procurement, warehouse, sales and menu settings user admin. Testing with user access admin procurement id level (2) can be seen in Fig. 8.

\footnotetext{
* Corresponding author
} 


\section{Journal of Computer Networks, Architecture and High Performance Computing}

Volume 3, Number 2, July 2021

https://doi.org/10.47709/cnahpc.v3i2.1006
Submitted : 28 June 2021

Accepted : 6 July 2021

Published : 5 August 2021

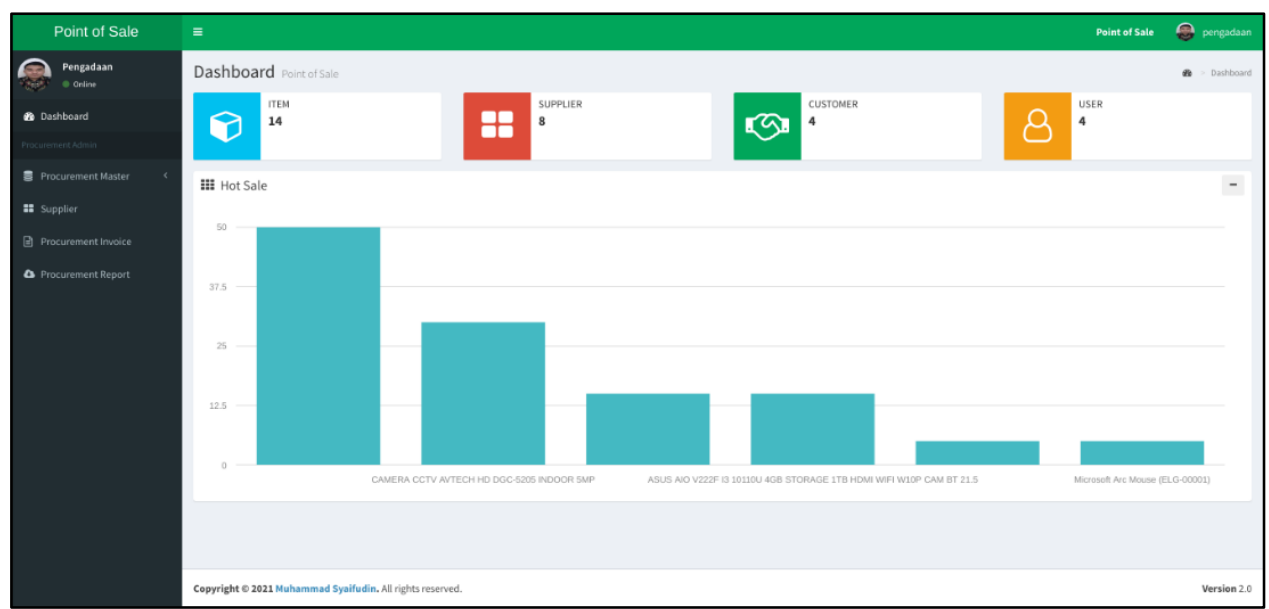

Fig. 8. Procurement admin dashboard page view

On the page dashboard user admin procurement shows there is only a menu feature owned by the procurement admin itself and cannot access other division menu features. Testing with user access admin warehouse id level (3) can be seen in Fig. 9 .

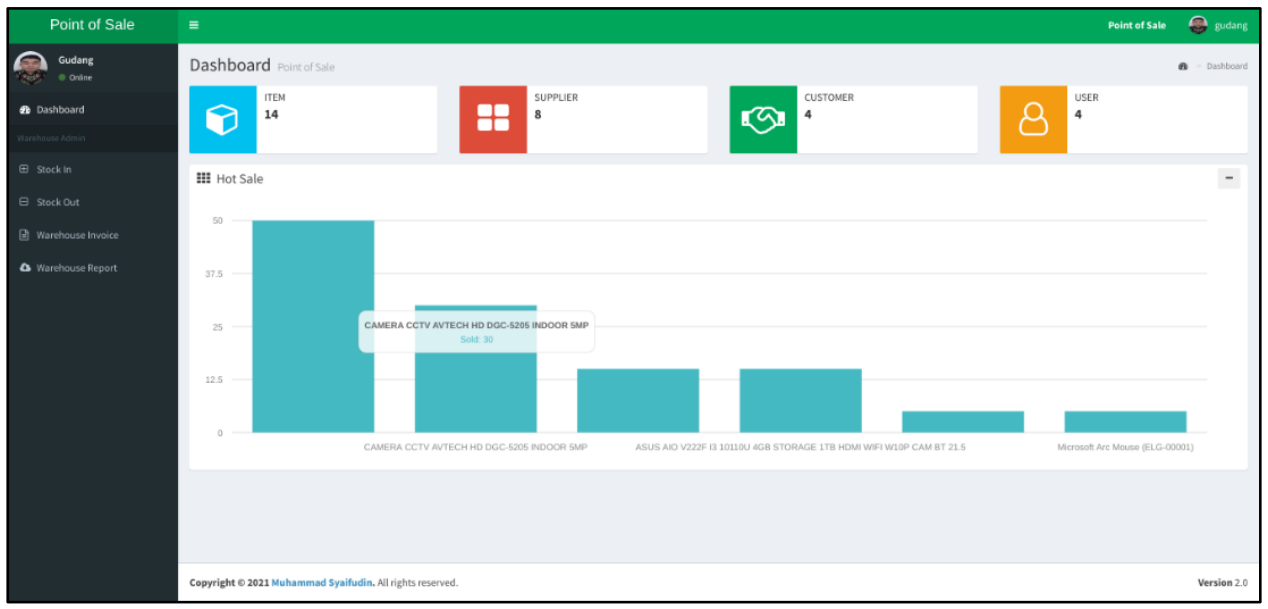

Fig. 9. Warehouse Admin Dashboard Page View

On the page dashboard user admin warehouse shows there is only a menu feature owned by the procurement admin itself and cannot access other division menu features. Testing with user access admin sales id level (4) can be seen in Fig. 10.

* Corresponding author 


\section{Journal of Computer Networks, Architecture and High Performance Computing}

Volume 3, Number 2, July 2021

https://doi.org/10.47709/cnahpc.v3i2.1006
Submitted : 28 June 2021

Accepted : 6 July 2021

Published : 5 August 2021

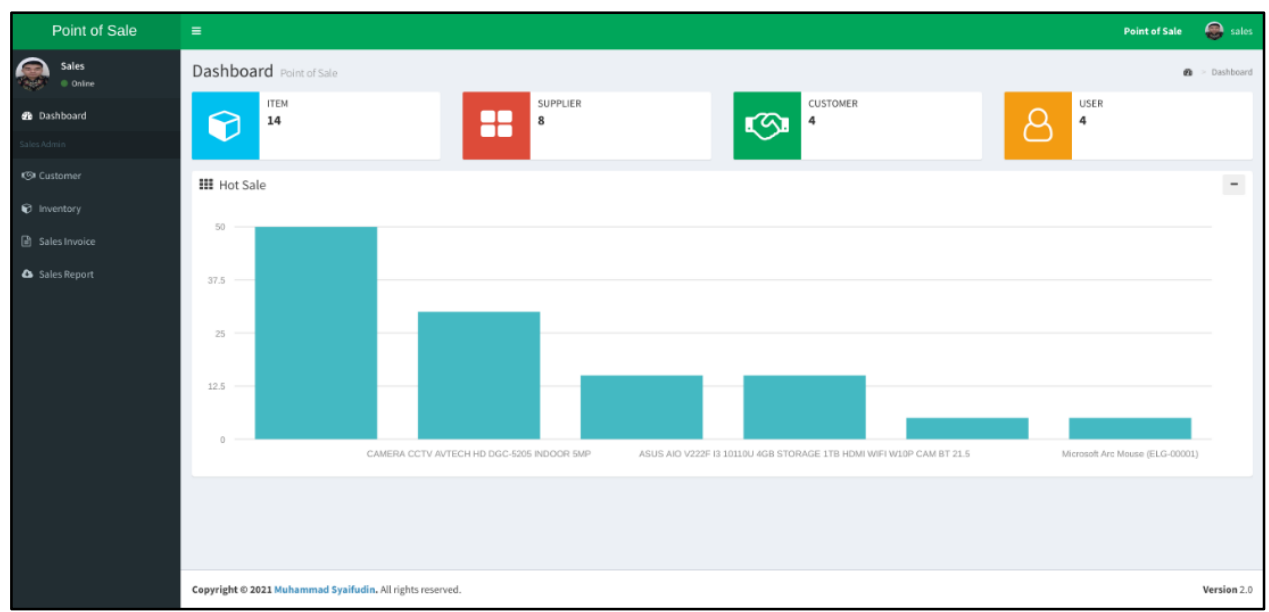

Fig. 10. Warehouse Admin Dashboard Page View

\section{DISUCCION}

Lighthouse testing (dev tools google chrome) is an automatic open source tool (aid) to improve the quality of web applications. It can also run it as a Chrome Extension or from the command line. Giving Lighthouse a URL that you want to test or audit, lighthouse runs a series of tests on the page, then generates a report on how well the page is running. From here it can use tests that do not pass as an indicator of what can be done to improve the web application. The following can be seen in Fig. 11.

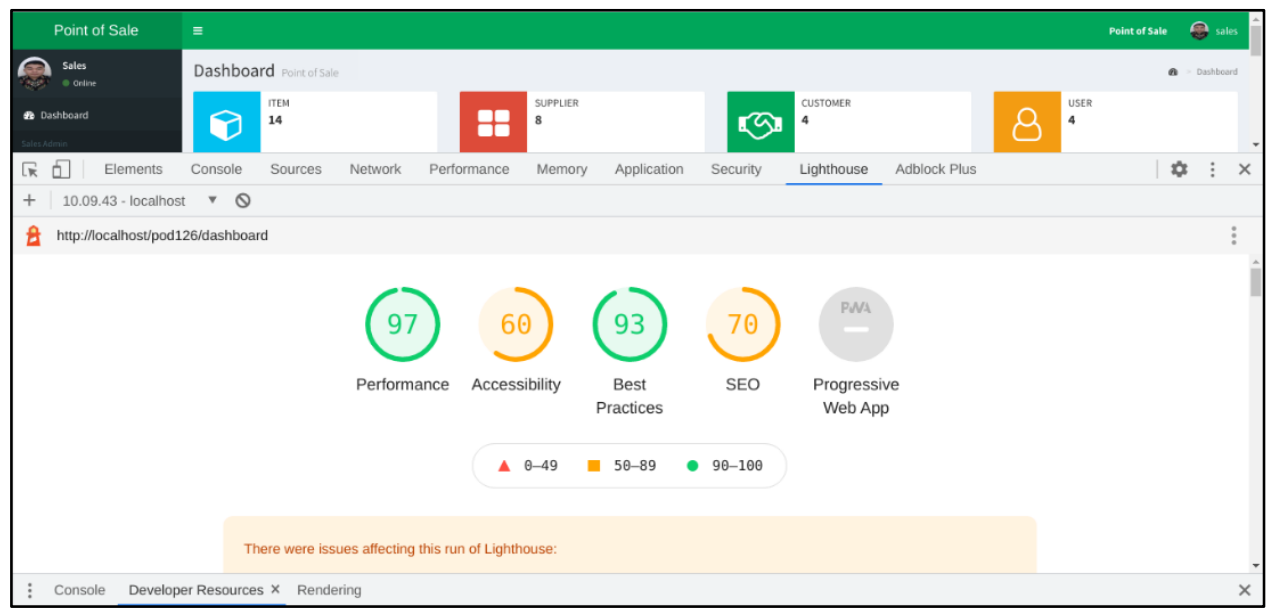

Fig. 11. Lighthouse Testing Homework

In lighthouse testing showed a good presentation is not perfect but it can be said good because above the presentation shows above average - the minimum average that has been determined is 60 - 97 while the reference percentage of web application eligibility is $0-49$.

\section{CONCLUSION}

Web Application that can login user admin with access role each - each user admin who has been determined so as to help the admin to access such as input data, compile supplier data, make procurement invoices, make a report creation process, and help the supervisor to do CRUD user admin, do the process of accessing data admin procurement, warehouse admin and sales admin. Web Application can separate user admin access features that have been specified 


\section{Journal of Computer Networks, Architecture and High Performance Computing}

Volume 3, Number 2, July 2021

https://doi.org/10.47709/cnahpc.v3i2.1006
Submitted : 28 June 2021

Accepted : 6 July 2021

Published : 5 August 2021

such as procurement admin, warehouse admin and sales admin. Web Display Application has also been responsive can customize laptop / PC / Mobile device. Testing using lighthouse to perform by 97\% showed that the application designed to have a good performance for display results, and the access in the web Point of Sale value of $60 \%$ indicates that the process related to responsive between users is appropriate both using PC / Tablet / mobile

\section{REFERENCES}

ANKURKAR, S. K. (2015). Evolving Web Applications with AJAX - A Review. International Journal of Innovative Research in Science, Engineering and Technology, 4(11), 11087-11093. https://doi.org/10.15680/ijirset.2015.0411030

Arrhioui, K., Mbarki, S., Betari, O., Roubi, S., \& Erramdani, M. (2017). A Model Driven Approach for Modeling and Generating PHP CodeIgniter based Applications. Transactions on Machine Learning and Artificial Intelligence, 5(4). https://doi.org/10.14738/tmlai.54.3189

Benmoussa, K., Laaziri, M., Khoulji, S., Larbi, K. M., \& Yamami, A. El. (2019). A new model for the selection of web development frameworks: application to PHP frameworks. International Journal of Electrical and Computer Engineering (IJECE), 9(1), 695. https://doi.org/10.11591/ijece.v9i1.pp695-703

Bhavsar, K., Shah, V., \& Gopalan, S. (2020). Scrumbanfall: An Agile Integration of Scrum and Kanban with Waterfall in Software Engineering. International Journal of Innovative Technology and Exploring Engineering, 9(4), 2075-2084. https://doi.org/10.35940/ijitee.d1437.029420

Industry, T. O. (2011). Current Trends in. Cactus Tourism Journal, 7(July), 82-84.

Journal, E., Chain, S., Vol, M., Centre, E., \& Uk, D. (2017). Role of Electronic Point of Sale on Supply Chain Performance in. 5(2), 19-55.

Kabir, M. A., \& Han, B. (2016). An improved usability evaluation model for point-of-sale systems. International Journal of Smart Home, 10(7), 269-282. https://doi.org/10.14257/ijsh.2016.10.7.27

Kambivi, H., Junirianto, E., \& Fadhliyah, N. R. (2020). Development of Inventory Management Application Points of Sale Using Laravel. Tepian, 1(1), 9-17.

Miguel, G., Cruz, T. Dela, Dumaplin, T. B., Gaerlan, P. V. T., \& Oliver, M. (2019). Inventory Management System with POS. 6(4), 8739-8745.

Paramita, A. S. (2019). Cloud computing-based point-of-sales readiness for Surabaya's small/medium enterprises. International Journal of Advanced Trends in Computer Science and Engineering, 8(1.5 Special Issue), 333338. https://doi.org/10.30534/ijatcse/2019/5581.52019

Rodič, B., Marinova, G., \& Chikov, O. (2017). Algorithms and Decision Making Methods for Filter Design Tool Selection for a Given Specification in Online-CADCOM Platform. 247-251.

Singh, B., Kaur, P., \& Kumar, H. (2017). Simulated Characteristics of a Nonlinear Directional Coupler Based Optical Switch. VI(Vi), 1-5.

Sison, P. D. T., Oreiro, K. P., Camalit, J. C. Z., \& Ng, G. C. (2019). a Problem Oriented Approach To Implementing an Inventory and Point-of-Sale System for Company Kcp. Innovatus (ISSN: 2651-6993), 2(1), 95-100. https://doi.org/10.5281/zenodo.4484959

STOICA, M., GHILIC-MICU, B., MIRCEA, M., \& USCATU, C. (2016). Analyzing Agile Development - from Waterfall Style to Scrumban. Informatica Economica, 20(4/2016), 5-14. https://doi.org/10.12948/issn14531305/20.4.2016.01

Thakir Mahmood, M., Ibrahem Ashour, O., \& Bayat, O. (2019). Design and Implementation of Web Based For Intermediate Online Shop with Laravel Framework. Int. Journal of Comp. Science \& Mobile Computing, 8(3), 124-133. www.ijesmc.com

\footnotetext{
* Corresponding author
} 